\title{
LA "REDUCCIÓN A LA INMANENCIA" EN HUSSERL
}

La reducción fenomenológica no es un proceso simple, puede verse desde diferentes aspectos que expresan pasos distintos. Es, a la vez, paso de lo simplemente mentado a lo dado en la evidenciá, del ser relativo al ser absoluto, del mundo como suma de realidades a su origen constituyente y fuente de sentido, del yo perdido en el mundo al yo consciente de sí mismo, etc. Con el mismo término Husserl designa un complejo cambio de actitud que puede mostrar ora una, ora otra faceta, sin agotarse en ninguna. Con todo, el primer aspecto en que se presentó la reducción marcó una huella decisiva en todas las exposiciones posteriores. Desde las lecciones de Gottinga, de 1907, en que Husserl esbozó la primera exposición de la reducción fenomenológica, aparecía ésta como una reducción a la inmanencia de la conciencia.

Por desgracia, el término "inmanencia" nunca llegó a ser precisado suficientemente. Husserl lo usa a menudo en sentidos diferentes, sin advertirlo. Muchas perplejidades que suscita la comprensión de la reducción provienen de esa ambigüedad que arrastra desde sus primeras exposiciones. Algo más grave quizás: creemos que la interpretación idealista trascendental que Husserl da de su propio método tiene uno de sus orígenes en la inicial confusión en los usos del término "inmanencia". Distinguir los varios sentidos en que es usada esa palabra, permitirá, sin duda, comprender el verdadero alcance de la "reducción a la inmanencia". Con ello, tal vez logremos arrojar también alguna luz sobre la pertinencia de la interpretación idealista que Husserl elige.

Pero para comprender el sentido de la reducción es menester, antes, aclarar sucintamente sus relaciones con la actitud natural primero, con la reducción eidética, después.

\section{La actitud natural y la epojé fenomenológica}

Cotidianamente vivimos en "actitud natural". Es nuestra posición espontánea, normal ante el mundo circundante. Previa a toda crítica, se nos impone sin discusión, como la más obvia y comprensible de suyo. Allí estoy yo ante una muchedumbre de cosas que me rodean por todas partes; no sólo tienen carácter teórico, también práctico; pues no sólo me encuentro con cosas naturales, sino con objetos provistos de valores y significados humanos, útiles, artificios, construcciones, personas. Todo ello constituye el ámbito en que me muevo, mi "mundo en torno", el cual comprende tanto naturaleza como cultura. 
Todas esas cosas existen efectivamente, tienen Wirklichkeit. Jamás se me ocurrirá espontáneamente dudar de ello; su existencia se me presenta como un factum, un hecho puro y simple; me encuentro con ella y en ella, la hallo sin quererlo. De tal modo que mi creencia en ella no depende de un juicio expreso por mi parte; acompaña silenciosamente todos mis actos mientras me dejo vivir en el seno del mundo. Se trata, pues, de una posición de existencia "potencial", latente, de la captación antepredicativa de un dato originario. En cualquier momento puedo convertir esa tesis potencial en un juicio actual. ${ }^{1}$ Si hago esto, sólo convertiré en juicio expreso la experiencia originaria de aquel encontrarme con el mundo. Esa presencia del mundo no se reduce, por otra parte, a la estrecha esfera de lo que actualmente conozco; el mundo se prolonga en un horizonte de existencia efectiva indeterminada que va perdiéndose en lo ilimitado. ${ }^{2}$

El modo de ser efectivo del mundo en torno es, ante todo, estar presente "ahí delante", ser vorhanden. Por el simple hecho de vivir, me encuentro en medio de cosas que estaban ahí previamente y se me presentan; son lo otro, lo distinto y separado que se me opone. Delante de mí, el espectáculo sin fin de las cosas, existiendo de hecho, imponiéndome calladamente su presencia: "están las cosas corpóreas, en una u otra distribución espacial, para mí simplemente de ahí, 'ahí adelante' (vorhanden)', lo mismo si me ocupo de ellas o no. ${ }^{3} \mathrm{El}$ mundo es el conjunto de cosas que existen "ahí adelante", la suma de objetos con que me encuentro. Mi conocimiento de su estar ahí es el reconocimiento de un mero hecho, de una contingencia empírica; el mundo es objeto de un conocimiento fáctico.

Mas la actitud natural no se contenta con esa presencia efectiva del mundo. Además, añade una tesis expresa de realidad (Realität) ${ }^{4}$ Creemos que todas las cosas presentes, sean actuales o pertenezcan al horizonte del mundo que se aleja hacia lo indeterminado, pueden agregarse, yuxtaponerse unas atras otras para formar una suma que se extiende en un espacio y transcurre en un tiempo unos. En ese ámbito espacio-temporal unitario, cada cosa ocupa un lugar objetivo preciso; ya no se limita con estar ahí, ante mí, además está al lado de otras cosas entre las que tiene su puesto determinado en el todo. Cada cosa está contenida en el gran continente universal: el mundo. Entonces, digo que la cosa es real. Ser real quiere decir: estar ahí delante $\mathrm{y}$, además, estar insertado en el mundo espacio-temporal uno. Y el mundo todo lo abarca; ahora ya no está simplemente

1 Ideen..., M. Nijhoff, Den Haag, 1950, t. I, pp. 63-64 (traducción de J. Gaos, ed. Fondo de Cultura Económica, México, 1949, p. 70). En lo sucesivo citaremos: Id.

2 Id., p. 58 (trad., p. 65).

${ }^{3}$ Id., p. 57 (trad., p. 64). Véase también p. 59 (trad., p. 66),

4 En alemán, "realidad" puede decirse de dos maneras: "Wirclichkeit" y "Realität". La primera designa, en la terminología de Husserl, todo lo que efectivamente existe; la traduciremos por "existencia efectiva". La segunda designa el modo de ser que correspondería al mundo en la actitud natural: la traduciremos por "realidad". Para los distintos usos de estos términos en Husserl, se consultará con fruto: E. Mayz Vallenilla, Fenomenología del Conocimiento, Universidad Central de Venezuela, Caracas, 1956, notas a las pp. 69 y 131. 
ante mí, me engloba y me contiene. Pues yo mismo estoy inserto en él, ocupo un sitio al lado de las otras cosas, como un objeto más. Soy otra cosa que también está ahí, encajada en el ámbito cósmico. $\mathrm{Y}$ todas mis vivencias, mis acciones y pasiones, son igualmente procesos reales de esa cosa psíquica peculiar. Lo mismo vale para los demás sujetos; concibo su mundo circundante como idéntico con el mío; de tal suerte que el mundo real es aquel en que toda circunstancia coincide, es el mundo "objetivo". Ponemos en común todos los hombres "una realidad espacial y temporal objetiva como el mundo circundante de todos nosotros, que está ahí y al que pertenecemos nosotros mismos".5 El mundo es el agregado de cosas espacio-temporales entre las cuales me cuento; abarca cosas naturales y objetos culturales, hombres, plantas e instituciones; todo lo contiene: es "la totalidad de las realidades". 6

Notemos que ahora "realidad" ya no significa solamente la existencia efectiva de las cosas. A la simple presencia de las cosas, hemos añadido una nueva determinación, un significado peculiar que no estaba dado en la experiencia originaria. Entendemos el existir de algo en el "sentido" de estar en medio de un mundo objetivo unitario que abarca tanto al objeto en cuestión como al sujeto ante el cual se da; existir consiste en ser cosa entre cosas dentro de una suma. Esa es estrictamente la "tesis de realidad". Para ella, no hay más ser verdadero que el ser real así concebido. "Coinciden en esa [actitud] los conceptos 'ser verdadero', 'ser real' y -como todo lo real se funde en la unidad del mundo- 'ser en el mundo" "7 Al estar ahi delante antepredicativo se le da el sentido de existencia en el mundo antes de mí y fuera dé mí. El mundo ya no está simplemente presente; además, es realmente, existe de por sí, sin que la aparición o desaparición de una de sus partículas, el sujeto, le afecte: "pues obviamente el mundo es lo que es, en y para sí, vivamos o muramos, conozcámoslo o no": 8 tal es la tesis general de la actitud natural.

Curiosa perspectiva ésta; que ya no veo las cosas desde mí, sino todo desde el mundo y a mí mismo en él. Ya no es él mi espectáculo, yo quedo incluido en la escena... Como si me elevara a una lejanísima atalaya y eliminara mi personal perspectiva, de modo que las cosas se mostraran como son en sí y por sí mismas, y yo mismo, allá abajo, surgiera ante mi vista, cual otro objeto perdido en la muchedumbre.

La "reducción fenomenológica" o "reducción trascendental" 9 es una conversión: una transformación radical de nuestra actitud frente al mundo; abandona-

5 Id., p. 62 (trad., p. 68).

${ }^{6}$ Erste Philosophie, M. Nijhoff, Den Haag, 1956, t. I, p. 244. En lo sucesivo citaremos: $E P$.

7 Id., p. 10 (trad., p. 17).

8 EP., p. 245.

9 Husserl emplea a veces el término "reducción fenomenológica" para referirse a la reducción eidética. Para evitar equívocos, nosotros usaremos los términos "reducción fenomenológica" y "reducción trascendental" como equivalentes; de ambos abría que distinguir la "reducción eidética". 
mos nuestra postura espontánea, natural, frente a las cosas para asumir la postura propiamente filosófica. Ante todo presentará, pues, una faceta negativa: la que corresponde al movimiento de abandono de una actitud previa. La epojé es la reducción por cuanto mira hacia la postura que niega, es la función catártica, depuradora del método.

Epojé, viejo término que significa "abstención o suspensión de juicio", es la operación crítica por excelencia. Consiste en la purificación cabal de las opiniones, prejuicios, ideas heredadas o espontáneas que aceptamos sin discusión, con el fin de acceder a un saber sin supuestos. Es la suspensión de todas nuestras creencias mientras no puedan presentarse con la garantía innegable de la evidencia. Todo un mundo de saber y de opinión, trasmitido de mano en mano, confirmado sin cesar por nuestras propensiones naturales inconscientes, se levanta sobre nosotros imponiéndonos su peso. Si queremos alcanzar nuestra propia verdad, aquella que se funde en muestra personal visión de las cosas mismas, debemos cuanto antes liberarnos de él; sólo así nos pondremos en franquía para la verdad. La suspensión del juicio es la tarea crítica que ha de preceder a toda filosofía auténtica; en su sentido liberador se emparenta directamente con la ironía socrática y la duda cartesiana. Como esos métodos, tienen un doble fin: alcanzar un saber sin supuestos y liberar el espíritu de la sujeción a las opiniones que lo enajenan. En cuanto implica la abstención de pronunciarse acerca de las filosofías anteriores, Husserl la llama "epojé filosófica".10

$\mathrm{Y}$ entre todos los supuestos, el más arraigado en nuestra mente es aquel que no ponemos en discusión por parecernos el más "obvio" y "natural": la creencia en la realidad del mundo. Por ello, la epojé fenomenológica consiste fundamentalmente en la suspensión de la tesis general de la actitud natural. Al practicarla, no reemplazamos nuestra creencia afirmativa por otra negativa o por una actitud escéptica. No negamos ni dudamos de la realidad del mundo, simplemente hacemos caso omiso de nuestra creencia, no la tomamos en consideración... precisamente por ser una mera creencia. Ni siquiera tenemos por qué abandonarla; podemos seguirla aceptando para los usos de nuestra vida cotidiana; simplemente dejamos de concederle validez objetiva para tomarla como lo que es: una adhesión personal. "No abandonamos la tesis que hemos practicado, no hacemos cambiar en nada nuestra convicción, que sigue siendo la que es mientras no introducimos nuevas razones de juzgar, que es justo lo que no hacemos. Y sin embargo, experimenta la tesis una modificación - mientras sigue siendo la que es, la ponemos, por decirlo así 'fuera de juego', la 'desconectamos', la 'colocamos entre paréntesis'. La tesis sigue existiendo, como lo colocado entre paréntesis sigue existiendo dentro del paréntesis como lo desconectado sigue existiendo fuera de la conexión. Podemos decir también: la tesis es una vivencia, pero no hacemos de ella 'ningún uso'." "1

10 Id., pp. 40-41 (trad., pp. 46-47).

11 Id., p. 65 (trad., p. 71). 
Al suspender la tesis de realidad, queda afectado por la epojé todo el mundo en la medida en que se fundaba en ella: la naturaleza como conjunto de cosas físicas situadas en el espacio-tiempo unitarios de la realidad cósmica, el mundo cultural como suma de los productos reales del hombre, mi propio cuerpo como cosa entre cosas, mis procesos psíquicos considerados como sucesos de una entidad real. "El mundo entero puesto en la actitud natural... no vale en [el sentido de "no tiene validez"] para nosotros ahora nada; sin ponerlo a prueba, pero también sin discutirlo, debe quedar colocado entre paréntesis." 12

Hemos suspendido la tesis general de realidad $y$, sin embargo, no hemos perdido nada. Aunque ya no concedemos validez a nuestra tesis, todos los datos y asunciones que comprendía la actitud natural siguen presentes a nuestro conocimiento. Nuestras ideas, creencias, conjeturas, incluyendo la creencia en la realidad, están aún ahí para ser analizadas. Sólo que ahora se presentan como vivencias dirigidas a sus objetos, acerca de cuya pretensión de verdad tenemos aún que juzgar. "Yo, en cuanto sujeto que reflexiona filosóficamente, ya no llevo a cabo, ya no concedo validez a la creencia natural en la realidad que es inherente a la experiencia del mundo, a pesar de lo cual esta creencia sigue estando ahí y es aprendida por la mirada de la atención. Igualmente acontece con todas las restantes asunciones que pertenecen a la corriente de mi vida, además de las constitutivas de la experiencia del mundo: con mis representaciones no intuitivas, juicios, valoraciones, resoluciones, determinaciones de fines y medios, etc..." 13 Todo está presente, pero nos abstenemos de concederle una validez que rebase lo que muestra a la intuición. Del mismo modo, el mundo entero sigue experimentado por nosotros, con los mismos contenidos que antes, sólo que ahora "cambia de signo". Antes lo interpretábamos como el todo de las realidades, ahora sólo lo aceptamos tal como se da y en los límites en que se da. El mundo queda como un conjunto de datos experimentados, sin que les añada la significiación de existir en sí y para sí mismos. El mundo subsiste en su integridad: ofrece la misma riqueza a la percepción, está animado de los mismos valores humanos, responde a las mismas reglas y alberga idéntica poesía; pero todo ello está ahora reducido a los límites en que se ofrece: datos de intuición los unos, actos de conciencia no cumplidos los otros, cosa entre cosas ninguno. $\mathrm{Y}$ yo también permanezco. Claro que ya no soy un bulto que ocupa un espacio y está yuxtapuesto a otras cosas. Soy un foco de actos intencionales dirigidos al mundo en torno y, en él, a mi propio ser humano. Mis vivencias ya no se interpretan como procesos cambiantes de una cosa en el mundo sino comb lo que muestran a la intuición directa: vida intencional abierta a las cosas. Quedan, después de la epojé, dos cosas: vida intencional dirigida al mundo y el mundo como su correlato. Ya no puedo considerar el mundo como conjunto de entes en sí y para sí; con todo, está pre-

12 Id., p. 69 (trad., p. 74).

13 Cartesianische Meditationen, M. Nijhoff, Den Haag, 1950, p. 59. (traducción de J. Gaos, ed. Colegio de México, 1942, p. 35). En lo sucesivo citaremos: CM. 
sente como algo a lo que dirigen mis actos y que suscita mis vivencias: está el mundo tal como es para mí. "Todo lo perteneciente al mundo, toda realidad espacio-temporal existe para mí, es decir, vale para mí, y vale para mí porque la experimento, la percibo, me acuerdo de ella, pienso de alguna manera en ella, la enjuicio, la valoro, la apetezco, etc.".14 O - como dirá Husserl con mayor precisión más tarde- el mundo entero se ha vuelto fenómeno, esto es, presencia ante la vida que se le abre. ${ }^{15}$

Cuidémonos, por fin, de un par de equívocos. Al suprimir la tesis de realidad, el conjunto de fenómenos que quedan, podemos calificarlos de "irreales". Pero no caigamos en un equívoco, fácil en castellano, imposible en alemán. Aunque dejan de ser "reales" (realen) en el sentido de la tesis de la actitud natural, no dejan de serlo en el sentido de "efectivamente existentes" (wirklichen). Más aún, sólo ahora cobran su verdadera "realidad" en este sentido de plena y fundada existencia. Cuidémonos, pues, de hacer del concepto. de "irrealidad" un sinónimo de "apariencia", "ilusión" o "existencia confusa". Por lo contrario, lo "irreal" es lo más efectivamente existente, lo verdaderamente real en sentido absoluto. Tampoco equivale a "imaginario" o "ideal". "Irreal" es tanto un dato de fantasía como de percepción, tanto una idea como un objeto espacial y material; la suspensión de realidad no convierte las cosas en fantasía; por lo contrario: deja cada cosa en el estado peculiar en que se muestra.

Por último, tampoco hemos renunciado definitivamente a la adhesión filosófica a la tesis de realidad. Sólo hemos suspendido nuestro juicio acerca de ella porque se presentaba como un presupuesto "obvio", no demostrado. Mas no hemos negado la posibilidad de su efectiva validez. Una vez que hayamos accedido a la esfera de lo dado sin supuestos, podremos volver a preguntarnos acerca de la categoría de "realidad" y su alcance efectivo. Tal vez entonces pódamos aceptarla con un nuevo sentido.

\section{Reducción eidética y reducción trascendental}

Husserl también emplea el término de "reducción" para designar el uso metódico de la abstracción ideatoria. La "reducción eidética" es el camino para pasar de los hechos a las esencias. Las relaciones entre "reducción eidética" y "reducción fenomenológica" o "trascendental" no son siempre tan claras como fuera de desearse y suelen dar lugar a algunos equívocos. Antes de seguir adelante, convendrá precisarlas.

Todo hecho está caracterizado por dos notas: individualidad y contingencia. Los hechos son las matters of fact del empirismo inglés. Su existencia es fáctica: podrían ser de otra manera, pero "de hecho" son así. Husserl suele a menudo

14 CM., p. 60 (trad., p. 37).

15 Die Krisis der europäischen Wissenschaften..., M. Nijhoff, Den Haag, 1954, p. 155. 
restringir la noción de "existencia" (Dasein, Existenz) al modo de ser contingente propio del hecho; opone, así, "esencia" a la pareja de conceptos "hecho-existencia". En este sentido, decir, por ejemplo, "la esencia no implica la existencia" querría decir: "La esencia no tiene individualidad ni contingencia, no es un hecho"; mas no podría significar que la esencia no sea; la esencia es plenamente, tiene Wirklichkeit. El modo de conocimiento de hechos es, por fin, siempre empírico y a posteriori: es la "experiencia". Experiencia es un conocimiento ligado siempre a casos singulares y "fácticos", es "aprehensión de existencias".16

A partir de un hecho puedo llegar a una esencia, esto es, a los predicables universales que le convienen necesariamente en cuanto es de tal o cual manera. "Un objeto individual no es meramente individual; un 'esto que está allí, un objeto que sólo se da una vez, tiene, en cuanto constituido 'en sí mismo' de tal o cual manera, su indole peculiar, su dosis de predicables esenciales, que necesitan convenirle...". ${ }^{17} \mathrm{La}$ esencia es aquello en que un hecho consiste, lo que es. Es universal y puede, por tanto, aplicarse a otros muchos individuos; está liberada de la existencia fáctica: "el poner y ante todo el aprehender intuitivamente esencias no implica en lo más mínimo el poner existencia individual alguna; las puras verdades esenciales no contienen la menor afirmación sobre hechos... ". 18 Las Investigaciones Lógicas mostraron, en efecto, que las esencias, objetos ideales, son en sí y que la validez de sus leyes es independiente de las leyes fácticas.

Ahora bien, todo lo que ponemos como real en la actitud natural es un hecho, pues no fuera concebible nada real que no sea individual y contingente. Pero esto no implica que los conceptos de realidad y facticidad sean equivalentes. Lo "real" es una especie del género "hecho". Reales son sólo aquellos hechos que se acompañan, además, de una tesis que los ponen como partes del mundo real. Y desde ahora podemos comprender que podría haber otra clase de procesos individuales desprovistos de esa tesis, que serían hechos e irreales. Si todo lo real es hecho (aunque no todo hecho sea real) es evidente que las esencias, por hacer abstracción de todo hecho, serán siempre irreales. Para significar esto, Husserl utiliza el mismo concepto de "existencia" en un segundo sentido: como el modo de ser de un hecho real. En este segundo sentido, decir que "la esencia no implica la existencia" significaría: "La esencia es indiferente a la realidad, es irreal." Esta acepción tiene sin duda, la palabra "existencia", cuando Husserl llama a la tesis de la actitud natural "tesis de existencia". Pero estas ambigüedades en el significado de los términos dan lugar a confusiones. Nosotros reservaremos el término "existencia", como opuesto a "esencia", para significar el modo de ser del hecho; podremos, por tanto, hablar de "existencia real" o de "existencia irreal". 19

16 Id., p. 17 (trad., p. 24). Véase también p. 45 (trad., p. 51).

17 Id., p. 12 (trad., p. 19).

18 Id., p. 17 (trad., p. 23).

19 A veces Husserl usa también el término "existencia" para referirse a lo dado en la percepción; entonces se opone a lo meramente imaginado, aumentando con ello la confusión (véase $I d$., pp. 16 y 89 ; trad., pp. 23 y 89 ). 
El paso a la esencia, la reducción eidética, es un procedimiento de irrealización, no porque haga a un lado expresamente lo real, sino porque, al abstraer de todo hecho, hace abstracción también de esa especie de hechos que son las realidades. La esencia es universal y no está comprometida en el plexo de relaciones temporo-espaciales del mundo natural. Con todo, podemos aún distinguir entre esencias de objetos reales y esencias de fenómenos no reales. Como todo lo real es trascendente y lo no real inmanente; podemos, pues, llamarlas: esencias trascendentales $y$ esencias inmanentes. Todo contenido real individual tiene su esencia correspondiente y toda intuición individual - aún la inadecuada- puede convertirse, por abstracción ideatoria, en intuición esencial. Así obtendremos esencias cuya verificación intuitiva en ejemplares individuales es inadecuada y que nos suministran un conocimiento de las cosas reales de que fueron abstraídas: son esencias transcendentes. Mientras que las esencias abstraídas de hechos inmanentes, cuya intuición es adecuada, suministrarán un conocimiento de lo inmanente y serán ellas mismas inmanentes. ${ }^{20}$ Así, a la distinción entre hechos reales y no reales corresponde la de sus esencias respectivas. No obstante, es obvio que no es propiamente la esencia la que es trascendente o real, sino el ejemplar individual que la cumple; ella misma es un "nuevo objeto" distinto de ese ejemplar y, puesto que ajeno a la existencia fáctica, irreal: Por eso, Husserl no hablará de "esencias reales" sino de "conocimiento esencial de algo real". ${ }^{21}$ En esta clase de conocimientos no se trata de juicios empíricos, sino de un juzgar eidético que se acompaña con la posición de la existencia real de lo individual. ${ }^{2}$ Al juicio eidético, cuyo objeto es ideal, se añade otro acto: la posición de realidad del ejemplar. Se trata, pues, de la aplicación de la esencia a algo trascendente. ${ }^{23}$ La esfera de lo eidético es siempre irreal, mas puede cumplirse intuitivamente, referirse simbólicamente a hechos indistintamente reales o irreales.

Por eso, aún antes de practicar la epojé fenomenológica, podemos usar del método eidético en actitud natural. Podemos, por ejemplo, aplicarlo a las vivencias psíquicas, sin dejar de considerarlas como procesos reales. ${ }^{24}$ Con ello, no accedemos a la fenomenología trascendental sino a una psicología eidética; ésta consiste en un conocimento de los procesos psíquicos reales por la intuición de sus esencias universales. Tal es el tipo de indagaciones en que se encontraba la primera edición de las Investigaciones Lógicas y con el cual se inició la fenomenología como "psicología descriptiva".

Para acceder a la fenomenología no basta, pues, con la reducción eidética; es menester otra reducción que, por así decirlo, cruce perpendicularmente a la

20 Id., pp. 13 y ss., $34-35,142$ y ss. (trad., pp. 20 y ss., 41,137 y,ss.).

21 Id., p. 7 (trad., p. 11).

$22 I d .$, p. 20 (trad., p. 26).

${ }^{23}$ Tal hace -según Husserl- la ciencia física, al aplicar los juicios puros de la matemática, que versan sobre objetos ideales, a los hechos reales (Id., pp. 20-21; trad., pp. 26-27).

24 Husserl aplica el método de esa manera en una página de las mismas Ideas... (p. 20 ; trad., p. 26). 
anterior. La reducción trascendental no pasa del hecho a la esencia, sino del hecho real a lo irreal (sea hecho o esencia). La reducción trascendental no prescinde del modo de ser fáctico, con su carácter empírico e individual; sólo afecta a la tesis de realidad que acompaña a la facticidad pura. Su resultado es la esfera de lo irreal, la cual comprende tanto esencias como hechos reducidos. La reducción trascendental se ejerce, pues, en principio sobre los ejemplares individuales de las esencias, no sobre éstas. En suma: puedo abolir todo hecho sin abolir la posición de realidad: estoy en la reducción eidética; o puedo abolir la posición de realidad sin abolir el hecho: estoy en la reducción trascendental. Ambas reducciones se cruzan al modo del siguiente esquema:

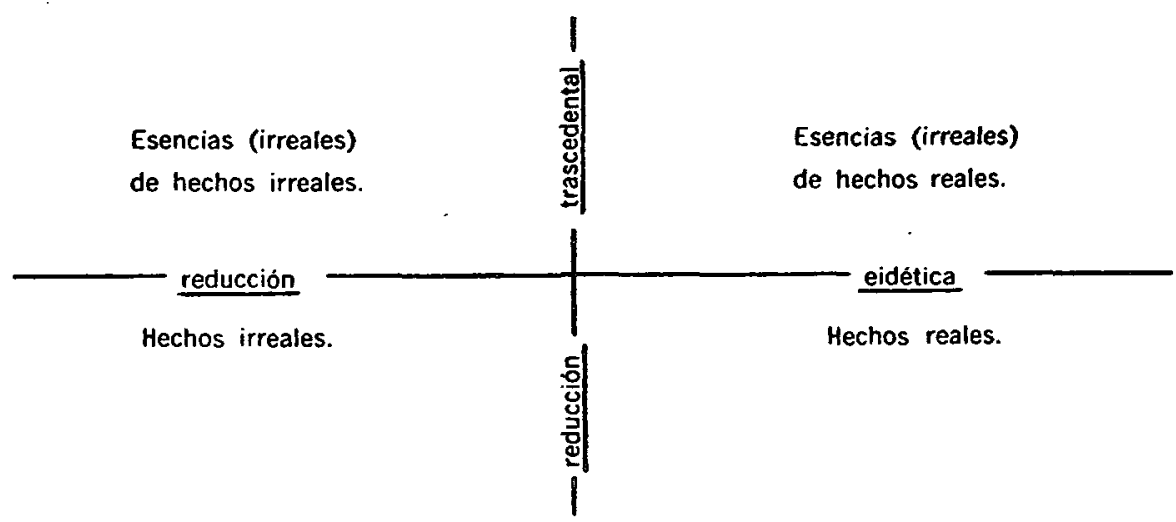

Vemos en este esquema cómo la reducción trascendental, al poner entre paréntesis toda realidad, prescinde también de las "esencias de hechos reales", esto es, de las que llamábamos antes, con Husserl, "esencias trascendentes". Se trata, en verdad, de un "ensanchamiento" de la reducción o de una "segunda reducción". ${ }^{25}$ Supone, en efecto, un paso suplementario. Por la epojé inicial sólo desconectamos el mundo de realidades individuales; ahora, en cambio, la epojé versa sobre un género de objetos en sí mismos irreales: las esencias trascendentes. Esta ampliación de la reducción es indispensable porque, como vimos, las esencias trascendentes se acompañan necesariamente de una tesis de realidad dirigida a sus objetos individuales. En verdad, no son las mismas esencias las que sufren la desconexión sino los actos de posición de realidad que las acompañan. Con ello se quita a toda esencia su inserción en el mundo de lo real al través de los ejemplares que de ellas.participen.

De suyo bastaría con la reducción eidética para alcanzar la esfera de los objetos cuya validez no depende de la realidad. Basta prescindir del carácter fáctico para llegar a lo ideal, pues, como toda realidad es fáctica, no puedo abolir el hecho sin suprimir, al mismo tiempo, la tesis de la realidad. La facticidad es

25 Id., pp. 143 a 147 (trad., pp. 138 a 141). 
una condición de la realidad, no a la inversa. En este sentido, lo eidético es una sección de la región de lo irreal que no se extiende a toda ella; puesto que lo irreal comprende también hechos reducidos. La reducción eidética es más exclusiva y más radical que la trascendental.

Por otra parte, la fenomenología pretende ser exclusivamente una ciencia de esencias; con el método eidético parecería que pudiéramos llegar a ella sin necesidad de mayores rodeos. De hecho, la fenomenología empezó con la reducción eidética y sólo más tarde se planteó la necesidad de otra reducción para resolver problemas que ese primer método dejaba abiertos. ¿Cuál es el sentido de este segundo paso?

Por lo pronto sólo haremos dos observaciones:

Primera: La reducción trascendental es indispensable para resolver un problema que la reducción eidética falla en solucionar: la relación entre la verdad en sí de lo esencial y su aparición en ejemplares individuales. Después del método eidético, las esencias siguen insertas en el mundo real y la validez pura del conocimiento eidético resulta un enigma. La reducción trascendental se ejerce sobre los hechos a partir de los cuales se abstrae la esencia; puede separar de la vivencia su momento real y proponer así, a las esencias una base depurada de la tesis de realidad, para que queden incluidas en el río de la conciencia sin convertirse, por ello, en procesos reales. Permite distinguir en el objeto conocido su momento real no dado de su momento irreal dado y proponer a las esencias una base de hechos puros en los cuales "existan", se cumplan, sin insertarse en el mundo de realidades.

Cierto que la fenomenología sólo trata de esencias, pero de esencias de hechos puros. "No una ciencia eidética de fenómenos reales, sino de fenómenos trascendentalmente reducidos es lo que debe ser nuestra fenomenología." ${ }^{26} \mathrm{La}$ segunda reducción es cronológicamente posterior a la primera, en la obra de Husserl, pero es lógicamente anterior porque le sirve-de base; es una condición de la posibilidad de la ciencia eidética.

Segunda: La reducción trascendental amplía el campo de lo puro (irreal) respecto de la región eidética; a las esencias añade los hechos puros. Permitiría, pues, una ciencia nueva de "hechos trascendentalmente reducidos". Esta sería una ciencia empírica, puesto que versaria sobre hechos individuales, pero pura, puesto que esos hechos no se toman como insertos en el mundo "real". Husserl dirá alguna vez que las "descripciones trascendentales tienen una significación empírica". ${ }^{27}$ La reducción eidética no permite explorar el campo de lo puro en toda su amplitud. Sólo la reducción fenomenológica propiamente dicha podrá revelar el rico mundo de la vida intencional pura, recuperar el flujo múltiple e individual de las vivencias tal y como se dan en la evidencia. Y sólo ella podrá

${ }^{26} I d .$, p. 6 (trad., p. 10).

27 CM., p. 104 (trad., p. 125). 
mostrar la relación de esa vida pura con el mundo que existe para ella, en toda su complejidad. Ella abre la posibilidad de explorar una nueva región del ser empirico: la intencionalidad pura y el mundo, como su correlato.

La reducción fenomenológica inicia, por lo tanto, una nueva tarea: el progresivo desvelamiento de la vida intencional que la actitud natural ocultaba. La epojé es sólo la faceta negativa del cambio de actitud. A ella deberá suceder la exploración de la nueva esfera que pone en franquía. Y Husserl designa a menudo esa esfera con el término "inmanencia". ¿Qué sentido tiene éste?

\section{La reducción a la inmanencia, desde la actitud natural}

El cambio radical de actitud obligaba a un cambio en los significados del lenguaje. Después de la epojé, muchas palabras empleadas en la actitud natural adquieren otro uso $y$, por ende, otro significado. Términos empleados para designar cosas y relaciones de un mundo real, ahora sólo pueden referirse con sentido a objetos y relaciones objetivas reducidas a la esfera de la vida intencional. Al no considerar este cambio de sentido surgen confusiones innecesarias. Por desgracia, Husserl no siempre se percata de ello. Términos centrales en su filosofía, como "inmanencia", son un ejemplo. Obviamente, no puede usarse con el mismo sentido antes y después de la reducción.

Nosotros deberemos distinguir entre los distintos sentidos del término que a menudo se confunden en los escritos husserlianos.

La reducción reemplaza una representación del mundo como continente en el cual se encuentra contenido el propio sujeto, por la presentación de la correlación entre el sujeto intencional y el mundo como su correlato. La primera aproximación para comprenderla será preguntarnos cómo se muestra para quien se encuentre todavia en actitud natural. ¿En qué consiste la reducción desde la perspectiva del mundo real que pone en cuestión? Para la posición de la actitud natural, la conciencia no puede ser sino un haz de procesos que forma parte del todo de las realidades; poner en cuestión la realidad del mundo cincundante parecerá un intento de estrecharse dentro de los límites de ese ente, reduciéndolo todo a "contenidos de conciencia". Así podemos distinguir entre lo que sea inmanente a la conciencia y lo que le sea trascendente. "Inmanencia" designa entonces la esfera "interior" al sujeto, el conjunto de sus vivencias; "trascendencia", todo lo que se encuentre "fuera" de la conciencia, las cosas reales "exteriores". Para quien se encuentre en actitud natural y, por ende, acepte esa distinción, la reducción parecerá prescindir de la segunda esfera para quedarse con la pura corriente de los contenidos de conciencia.

De parecida manera distinguiremos en nuestra conciencia dos clases de actos: los de "dirección inmanente" y los de "dirección trascendente". Los primeros serían aquellos cuyos objetos intencionales, si es que existen, pertenecen a la misma corriente de vivencia que ellos mismos; por ejemplo, un acto de reflexión diri- 
gido a otro acto o estado anímico. En estos actos el objeto intendido y el acto forman una unidad esencialmente dependiente; un elemento no puede existir sin el otro, pues son momentos correlativos del mismo proceso psíquico. Las vivencias de dirección trascendente, en cambio, se dirigen a objetos que no pertenecen a la corriente de las vivencias, que están "fuera" de ésta; por ejemplo, un acto referido a otro sujeto o a una cosa percibida. En ellos el objeto y la vivencia son esencialmente independientes; la cosa está realmente separada del acto; cada elemento podría subsistir sin el otro. ${ }^{28}$ La reducción a la inmanencia tendría que verse, según esta distinción, como la suspensión de la creencia en todo objeto "independiente" de las vivencias y el encierro del sujeto en éstas. El método fenomenológico provendría de reconocer la imposibilidad de que la conciencia salga "fuera" de sí para alcanzar un objeto trascendente a ella. La supresión de - la tesis de realidad sería un intento de reducir el conocimiento a la "interioridad" de la conciencia. Así verá la reducción quien aún no la haya practicado cabalmente $y$, por encontrarse en actitud natural, dé a los términos "inmanencia" y "trascendencia" un significado que sólo pueden tener sobre la base de la tesis de realidad.

Desde este punto de vista, la reducción podría interpretarse también como una respuesta a la tradicional aporía de la conciencia, planteada desde el escepticismo antiguo, que dice aproximadamente así ¿Cómo es posible que haya una relación objetiva entre conciencia y objeto, puesto que son dos esferas separadas, externas una a la otra y que existen con independencia esencial una de otra? La conciencia no puede, por principio, alcanzar el objeto trascendente. En efecto, todo objeto conocido, al ser conocido, se convierte en representación de una conciencia; para saber si ese objeto es real sería menester tener una representación de él y, por lo tanto, ya no conocería el objeto real sino su representación en la conciencia. No puedo, pues, salir del cerco de mis propias representaciones. En cuanto es consciente, el sujeto está constreñido a conocer sólo lo inmanente a sus propios "contenidos". Si ha de haber conocimiento de entes reales, la conciencia debe poder "salir fuera" de sí, abandonar el cerco de sus representaciones y captar, más allá de ellas, lo trascendente. Mas esto es imposible, pues la conciencia no puede saltar sobre sí misma; cualquier captación de lo trascendente lo convierte en representación inmanente. A la inversa, la cosa real, para ser conocida, debe introducir algunas de sus determinaciones en la esfera del sujeto, o comunicársele por medio de alguna imagen. Pero al hacer tal, abandona su ser trascendente; conocido no sería éste sino su representación en la conciencia. Es esencial al ser trascendente no poder ser conocido en su carácter de trascendente. En suma, o bien admitimos la trascendencia del objeto a la conciencia y, por ende, su incognoscibilidad, o bien nos reducimos a la inmanencia y negamos toda trascendencia. Desde la actitud natural, la reducción fenomenológica correspondería a este segundo miembro de la alternativa.

${ }^{28}$ Id., pp. 85-86 (trad., p. 86). 
Pero toda la "aporía" descansa en una distinción entre "inmanencia" y "trascendencia" que sólo puede tener sentido sobre la base de la posición de realidad, que la epojé debía suspender. Cierto que Husserl introduce esa distinción, en las Ideas, después de tratar de la epojé lo que hace pensar que se refiere a la conciencia ya reducida fenomenológicamente. Pero esto sería una confusión. Al inicio del capítulo dedicado a la distinción entre "inmanencia" y "trascendencia" leemos: "Empezamos con una serie de consideraciones dentro de las cuales no nos fatigaremos con ninguna epojé fenomenológica. Estamos dirigidos de un modo natural al 'mundo real' y llevamos a cabo, sin dejar la actitud natural, una reflexión psicológica sobre nuestro yo y sus vivencias." Más adelante, ya en plena exposición, volvemos a leer: "No hemos abandonado el terreno de la actitud natural." ${ }^{29}$ Como señalaba Eugen Fink, esa distinción supone un retorno a la actitud natural que tiene por fin destacar una característica real de la intencionalidad que permita comprender mejor posteriormente otra característica trascendental análoga. ${ }^{30}$ Las confusiones provienen de que, por desgracia, este punto no se encuentra precisado con suficiente claridad en las Ideas.

La "aporia" del conocimiento sólo tiene sentido en la actitud natural, pero carece de él desde el momento en que nos percatamos de lo infundado de esa actitud. Sólo entonces comprendemos que, por fundarse en la posición de realidad, la distinción entre "inmanencia" y "trascendencia", en los sentidos indicados, entraña un círculo. En efecto, postula, por una parte, la existencia del ser trascendente y exige un conocimiento de él; pero, por otra parte, entiende por ser trascendente algo por principio "externo" e independiente del conocimiento. Al considerar a la conciencia reducida a sus contenidos, sigue concibiéndola desde la perspectiva del mundo real trascendente; esto es, la interpreta como una esfera de procesos reales en el mundo, cerrado dentro de ciertos límites y rodeados por cosas externas sin relación esencial con ellos. La conciencia se figura como un pequeño continente contenido a su vez en el todo de las realidades. La "aporia" expresa precisamente la imposibilidad de que los contenidos de esa partícula del mundo salgan fuera de ella, y esta imposibilidad se funda en la previa representación de un mundo exterior real en el cual está incluida la conciencia. El círculo es patente: de la idea de la conciencia como continente cerrado se deriva la imposibilidad de que salga fuera de sí, y de esta imposibilidad se deriva su encierro en sus contenidos. La distinción entre "inmanencia" y "trascendencia", en cl sentido hasta ahora indicado, sólo puede plantearse sobre un supuesto no fundado: la tesis general de la actitud natural. La aporía que origina subsistirá mientras mantengamos esa actitud, se disolverá al abandonarla. En efecto, para poder hablar con sentido de "contenidos" de conciencia o de "vivencias que per-

29 Id., pp. 74 y 87 (trad., pp. 77 y 88).

30 "Die phänomenologische Philosophie Edmunds Husserls in der gegenwärtigen Kritik", en Kant-Studien, t. XXXVIII, Berlin, 1933, p. 36. 
tenecen a la misma esfera que sus objetos", es menester suponer la totalidad de lo real dividida en dos regiones de entes, seguir admitiendo, por lo tanto, la realidad exterior a la conciencia. Por otra parte, para poder decir que un objeto no pertenece esencialmente a la corriente de las vivencias, es menester seguir concibiendo la posibilidad de un ser real. En suma, la distinción separa en dos la esfera de lo real: por una parte, el conjunto de procesos psíquicos subjetivos, por la otra, los procesos físicos objetivos.

Por eso, a quien se encuentre en actitud natural, la reducción fenomenológica puede parecer una simple operación de separación entre los procesos psíquicos y los físicos, que conduciría a una descripción psicológico-eidético de los contenidos de conciencia. "Reducción a la inmanencia" puede interpretarse en este sentido. Pero quien así la interpreta demuestra que no ha practicado la reducción. Al practicarla, tendría que abolir la tesis de realidad y, por ende, el sentido aceptado para los términos "inmanencia" y "trascendencia". Preguntemos ahora: ¿Qué sentido podrían tener esos términos para quien efectivamente haya suspendido esa actitud?

\section{La reducción a la inmanencia, desde la actitud fenomenológica}

La reducción fenomenológica no separa un sector de lo real, "trascendente", de otro sector "inmanente"; prescinde de poner la realidad tanto de las cosas "externas" como de los actos de conciencia. Con ello desgaja a la conciencia, justamente con su objeto "trascendente" de su inserción en un lugar del todo espacio-temporal unitario. El corte de la epojé no escinde verticalmente el mundo para separar los "contenidos" de conciencia de los entes que los trascienden; transcurre, por decirlo así, horizontalmente por todos los entes y actos, tanto por el sujeto como por sus objetos, para cortarles su dimensión de realidad. La relación entre el sujeto y su objeto trascendente queda levantada a otro nivel. De tal modo que el conocimiento ya no aparece como una relación exterior entre dos cosas localizadas en distintos lugares del espacio-tiempo mundano, sino como una estructura de referencia que comprende acto y objeto, en la cual ninguno de los términos es cosa y, por lo tanto, no se encuentra externamente separado dentro del mundo. La relación de conocimiento ya no se ve desde el mundo real sino desde la estructura de la intencionalidad.

Desde este punto de mira todo objeto conocido forma parte ipso facto de la estructura de la intencionalidad, como correlato de un acto de dar sentido; trátese de un objeto natural, de un producto cultural o de una vivencia. Un objeto que no perteneciera a ella sería simplemente algo no presente, meramente pensado y no dado, mas no sería una cosa real existente en algún lugar "externo" a la intencionalidad. Así, el objeto de los actos de dirección trascendente o bien está dado y en tal caso es objeto intencional, o bien no lo está y en tal 
caso es algo mentado y nada más; pero no está "fuera", no "trasciende" a la intencionalidad.

¿Qué es, entonces, lo que en actitud natural llamábamos "trascendente" a la conciencia? Simplemente un sentido intencional, una significación mentada. El mero dato sensible, en su pura materia o contenido sensorial (en su hyle como dice Husserl), es inmanente a la conciencia; el sensatum (lo sentido) es inseparable de la sensatio (la sensación), por que carece, por sí mismo, de intencionalidad. ${ }^{31}$ En este nivel puramente sensorial no hay objetos, sino sólo un campo sensible que no está referido a nada; si no rebasáramos este estadio de conocimiento, todo estaría "pegado" a la conciencia sin que hubiera objetos distintos de las vivencias sensibles mismas; todo sería inmanente. La dirección de trascendencia empieza cuando a la hyle sensible se añade una referencia objetiva de sentido. Entonces los elementos sensoriales (el sensatum) se refieren a un objeto del cual se consideran determinaciones. Entonces la conciencia pone a distancia sus objetos con los datos sensibles que forman parte de ellos. No hay naturalmente un objeto dado aparte de los datos sensibles y de la referencia intencional. Cuando, por ejemplo, refiero este color verde, esta superficie rugosa, esta figura espacial que se presenta en variadas perspectivas, al objeto "árbol", no se me da, además de esos contenidos sensibles, otro dato que fuera el árbol como tal; sólo hay una verificación del sentido intencional "árbol" por todos los contenidos dados $\mathrm{y}$, por consiguiente, la referencia de todos éstos al objeto entendido por ese sentido. Ahora bien, esa referencia de sentido puede acompañarse, en la actitud natural, de una posición de realidad; entonces pongo el árbol como un ente contenido dentro de un mundo y existente en sí y para sí; o puedo simplemente, en la actitud reducida, poner el mismo objeto como polo de referencia objetiva de la intención; entonces todo queda igual, sólo ha cambiado el significado de la referencia intencional. Así, por la epojé nos percatamos de que trascendente sólo es un sentido puesto: "Todas las unidades reales son 'unidades de sentido'." 32 Pero ese sentido no puede cumplirse, porque no le corresponde ningún dato. Se me da el conjunto de elementos percibidos que refiero al árbol, pero no se me da, además, algo real, en sí y para sí, detrás de esos datos. La reducción opera, pues, un cambio en el sentido intencional, no en lo dado; consiste en "una radical modificación de sentido". 33 Para decirlo mejor: la reducción pone al descubierto que lo "trascendente" no era más que un sentido no cumplido, una significación vacía, meramente simbólica. Como contraprueba de ello bastará una sencilla reflexión; una realidad trascendente dada supondría el cumplimiento de un acto intencional que consiste justamente en ponerla como algo independiente del acto intencional: esto es, naturalmente, un contrasentido. Se trata de una pretensión enteramente inverificable, por esencia. "Una realidad

31 Id., pp. 241 y ss. (trad., pp. 235 y ss.) e Investigaciones Lógicas, traducción García Morente y Gaos, Rev. de Occidente, Madrid, t. III, p. 136.

32 Id., p. 134 (trad., p. 129).

33 Id., p. 221 (trad., p. 216). 
absoluta es exactamente lo mismo que un cuadrado redondo. Realidad y mundo son, justo, aquí rótulos para ciertas unidades de sentido válidas. . ."34

Lo que en actitud natural llamábamos "trascendente" es simplemente algo no dado, más aún, algo que por su mismo sentido no puede nunca darse. La reducción consiste efectivamente en la supresión de toda "trascendencia"; pero ésta no significa más que abstención de juicio ante todo lo no dado. Hay que tomar los sentidos en el límite en que se dan y no dar por cumplido ningún sentido vacío. La vuelta a la "inmanencia" es retorno a lo dado. "Trascendencia" e "inmanencia" cobran ahora una acepción distinta a la que tenían en la actitud natural. "Hay otra trascendencia - dice Husserl- cuyo contrario es otra inmanencia distinta, a saber: el dato absoluto y claro, el darse a sí mismo en sentido absoluto. Este estar dado que excluye cualquier duda con sentido, este intuir y captar, de modo enteramente inmediato, la objetividad mentada misma tal como ella es, constituye el concepto de evidencia en sentido estricto, entendido como evidencia inmediata. Todo lo no evidente, el conocimiento que mienta o pone lo objetivo pero no lo intuye él mismo es... trascendente. Con él, vamos más allá de lo dado verdaderamente en cada caso, más allá de lo que ha de intuirse y captarse directamente." 35 Ahora, reducción a la inmanencia quiere decir reducción a lo dado. "Inmanencia" no es usado para designar una esfera de lo real; significa "el darse a sí mismo (Selbstgegebenheit) que se constituye en la evidencia". 36

Y lo que la actitud natural entendía por contenidos "inmanentes" a la conciencia no coincide con lo dado. En efecto, dado no es ningún "contenido" de conciencia, es decir ningún proceso encerrado en esa esfera peculiar de la realidad llamada "subjetividad". La conciencia, en la medida en que se la considere como un pequeño continente separado del resto del mundo por el cerco de sus representaciones, también queda puesta entre paréntesis por la epojé. Pues esa representación de la conciencia la pone como cosa entre las cosas y tal posición no encuentra evidencia que la cumpla. "No es ciertamente evidente toda percepción del yo, si se entiende por el yo lo que entiende todo el mundo y que todo el mundo cree percibir en la percepción del yo: la propia personalidad empírica"; porque, cuando se toman las vivencias por estados reales de un sujeto, todas sus percepciones "son apercibidas de un modo trascendente, no menos que las externas". ${ }^{37}$

Al pasar a la actitud fenomenológica "reducción a la inmanencia" no puede entenderse, por lo tanto, como delimitación en una esfera de interioridad a la conciencia, puesto que la epojé ha eliminado la distinción entre "interioridad" y "exterioridad" a la conciencia, fundada en la tesis de realidad. "Reducción a la

34 Id., p. 134 (trad., p. 129).

${ }^{35}$ Die Idee der Phänomelogie, M. Nijhoff, Den Haag, 1950, p. 35 . En lo sucesivo citaremos: IP.

36 IP., p. 5.

37 Investigaciones Lógicas, t. II, p. 248. Véase también p. 246. 
inmanencia" sólo puede usarse para designar un radical cambio del punto de vista: el paso de considerar el conocimiento como una relación exterior entre dos entes del mundo real, a ver el mundo real y la relación de conocimiento a partir de la vida intencional. Ésta constituye la esfera de lo dado y no puede ser "interior", a nada, pues cualquier región a la que que fuera interior estaría también dada en ella. Entonces nos percatamos de que las dos regiones de objetos de que hablábamos en actitud natural son a su vez "inmanentes" a la estructura de la intencionalidad, pues todo sentido ha de estar mentado en ella y todo objeto cumplido en ella. Si todo sentido y toda región de objetos es "inmanente" a la intencionalidad, las nociones mismas de "inmanencia" y "trascendencia" usadas en actitud natural pierden su sentido. La palabra "trascendencia" sólo puede aplicarse a los actos de sentido "de dirección trascendente", pero éstos son, ellos mismos, inmanentes a la intencionalidad. "Fuera" de la referencia intencional no hay nada; pero entonces, tampoco tiene sentido decir que haya algo "dentro" de ella. Habría que haber suprimido definitivamente esas expresiones, o haber precisado con claridad su nuevo uso. Por desgracia, Husserl no hace lo uno ni lo otro. Cuando aún habla de "inmanencia" después de la reducción e insiste en que todo es "inmanente a la conciencia pura", sigue empleando un lenguaje de la actitud natural en un nuevo contexto en que carece de sentido. Así, da lugar a que se comprenda la reducción como una limitación a una esfera de "contenidos" de conciencia y propicia que la fenomenología se interprete en un sentido idealista subjetivo.

\section{Sentido definitivo de "inmanencia"}

Con todo, después de la reducción, Husserl emplea también los términos "inmanencia" y "trascendencia" en una última accpción, enteramente distinta de las anteriores. Ambos términos designan sendas esferas "inmanentes" a la intencionalidad en el sentido del parágrafo anterior. No se trata de una distinción entre lo dado y lo no dado, sino entre dos formas de darse. Inmanente es ahora todo elemento que forme parte de la corriente de las vivencias; trascendente, todo elemento de los correlatos intencionales de esas vivencias no incluido en la corriente de las vivencias. Esta distinción no coincide con la de la actitud natural, pues ahora tanto la corriente de las vivencias como sus correlatos - cualesquiera que sean- son "inmanentes" a la vida intencional. La relación de vivencias inmanentes a correlatos trascendentes, en este nuevo sentido, forma una estructura de referencia intencional entre los dos términos que Husserl denomina "nóesis" y "nóema".

En lo inmanente, lo dado pertenece a la misma corriente de vivencias que los actos que pueden referirse a él; por ejemplo, en todas las notas inherentes a las vivencias de juzgar, sentir, querer, etc. Es la esfera de las cogitationes, a la cual pertenecen los elementos que constituyen ingredientes de las vivencias mis- 
mas. ${ }^{38}$ Las notas ingredientes de las cogitationes comprenden: por una parte, los contenidos materiales, inintencionales por ellos mismos, de la mera sensación; son la hyle o materia de las vivencias; por otra parte, los actos intencionales que se añaden a ella, los actos de dar sentido que animan la materia sensible: son los elementos de.la nóesis (elementos noéticos). ${ }^{39}$ Por supuesto que esta esfera inmanente, en el sentido de ingrediente, no coincide con la "experiencia interna" del psicólogo. También respecto de lo ingrediente hay que prescindir de las posiciones trascendentes que rebasan lo dado en la vivencia. Ingredientes son las vivencias irrealizadas, desinsertas ya de su locación en el mundo real, que no están, por consiguiente, alojadas junto a otras cosas "externas" sino abiertas a sus objetos intencionales.

$\mathrm{Y}$ no todo lo dado corresponde a los ingredientes de la vivencia. El campo de la vivencia no se restringe a las meras cogitationes; abarca también los objetos intendidos en ellas y dados en sí mismo: éstos son los objetos trascendentes en el sentido posterior a la reducción. El correlato intencional no forma parte integrante de las vivencias; todo lo contrario: precisamente en cuanto correlato es lo otro de ella. Que lo propio del acto intencional consiste en ir más allá de sí mismo para réferirse a un objeto distinto de sí: el objeto intencional. Intencional,dad es aprehensión de algo que está allende el acto o estado de conciencia; un acto es intencional cuando está tendido hacia el otro, cuando consiste en una pura referencia a algo por principio extraño. Hay que distinguir, pues, esta trascendencia del objeto intendido de la pretendida "trascendencia" a la conciencia de que hablaba la actitud natural. Esta última es la trascendencia de la cosa real que no consiste más que en un sentido vacío; aquella es la trascendencia de los objetos dados como no ingredientes de la vivencia. Se trata de una trascendencia a la cogitatio, mas no de una trascendencia a la vida intencional. Trascendente es "el objeto conocido que no está contenido como ingrediente en el acto de conocimiento... El acto de conocimiento, la cogitatio, tiene momentos ingredientes que lo constituyen como tales; la cosa, en cambio, que él mienta y que (en su caso) percibe, recuerda, etc., no puede encontrarse como algo que esté efectivamente en la misma cogitatio en cuanto vivencia, como una parte ingrediente de ella".40

Lo importante es que este objeto intencional, si se trata de algo "exterior", no puede ser un objeto distinto al que la actitud natural ponía como real. Al suprimir la tesis de realidad, ya no puedo distinguir entre el objeto conocido y alguna cosa real que le correspondiera en un "mundo externo". La intencionalidad

38 Husserl emplea el término "reel" (no confundir con "real") para referirse a todo lo inmanente en este sentido. Con ello quiere, sin duda, sugerir que se trata de la verdadera realidad frente a pseudo-realidad de lo trascendente. Con todo, en español resulta confuso traducirlo por algún término de la familia de "realidad". Es muy acertada la solución de Gaos quien, tomando en cuenta la nota inherente a todo lo "reel", lo traduce por "ingrediente". Seguimos esta traducción.

39 Id., p. 241 y ss.

40 IP., p. 35. 
no se refiere a otro objeto diferente del. que antes consideraba real, que viniera a tomar el lugar de éste; se refiere a la misma cosa, aunque con otro sentido. El objeto intencional es el mismo que antes ponía como real; mejor dicho, en verdad sólo hay un objeto, sea o no real: el objeto intendido. Es, pues, la misma cosa "trascendente" la que está ahora dada como objeto intencional. En su lugar no veo, en modo alguno, alguna "imagen" o "representación" que tomara en la conciencia las veces de la cosa "exterior". No hay un "doble" de la cosa intendido a una con la cosa. Sólo hay un acto de referencia y un término de esa referencia, sin que entre ellos se interponga nada. Por ejemplo, en la percepción-dice Husserl- "la cosa espacial que vemos es con toda su trascendencia algo percibido, algo dado en su propia persona a la conciencia. No se da en lugar de ella una imagen o un signo. No se subrogue al percibir, la conciencia del signo o de la imagen". ${ }^{41}$ Suponer ese intermediario fuera escindir en dos el acto simple de percepción. Tendríamos ahora, en su lugar, un acto dirigido a la cosa espacial y otro dirigido a su imagen; en verdad sólo hay una intención que señala la cosa misma que trasciende del acto. Esa cosa espacial está ahora, por supuesto, despojada de la tesis que la ponía como "fuera" de la conciencia, pero no por ello pasa a un hipotético "dentro". Simplemente está ahí presente en persona frente a la cogitatio, sin formar parte de ella.

El objeto intencional trascendente es el nóema. Las vivencias, por el hecho de tener un sentido, señalan a contenịdos no ingredientes. "La percepción, por ejemplo, tiene su nóema, en lo más bajo su sentido perceptivo, es decir lo percibido en cuanto tal. Igualmente tiene cada recuerdo lo recordado en cuanto tal, justo como suyo, exactamente como está 'mentado', como es 'consciente' en él; a su vez, el juzgar, lo juzgado en cuanto tal; el agrado, lo grato en cuanto tal, etc.". 12 El nóema ya no es cosa del mundo real y, sin embargo, conserva todos los elementos que antes se atribuían a la cosa "exterior". Por ejemplo, en la percepción de un árbol en flor, el nóema no es más que ese mismo árbol reducido a los elementos dados con evidencia en él. "También la vivencia de percepción fenomenológicamente reducida es percepción de este manzano en flor, en este jardín, etc., e igualmente el agrado reducido, agrado por este mismo árbol. Este no ha perdido ni el más leve matiz de todos sus elementos, cualidades, caracteres con los cuales aparecia en la percepción, era 'bello', 'seductor', etc., 'en' el agrado". 43

Por una parte, el nóema, en tanto no es algo real, no está "fuera" de la vivencia intencional, separado de ella, sino que es esencialmente dependiente de ella; no ponemos un árbol en sí aparte del árbol percibido en cuanto tal. Pero no es más ingrediente de la vivencia que el árbol real. Ni tampoco se distingue

41 Id., p. 98 (trad., p. 98 ).

42 Id., p. 219 (trad., p. 213).

43 Id., p. 221 (trad., p. 215).

4 Id., pp. 223 y ss., 241 y ss. (trad., pp. 217 y ss., 236 y ss.). 
del árbol real como si fuera la "mera apariencia" de éste. ${ }^{44}$ El noéma árbol es el árbol mismo que se da como tal ante la intencionalidad. El nóema es el ente mismo, no su sucedáneo. Es el objeto trascendente en la medida en que se hace patente el acto de conocer: el ente retraido a su plena potencia.

En la relación entre nóesis y nóema, se abre una posibilidad nueva de comprender el conocimiento de lo trascedendente. En cuanto nóema el ente trascendente se ofrece a la conciencia, en cuanto nóesis, la conciencia está referida al ente. Nóesis es la vivencia en la medida en que se abre hacia los otros; nóema es el ente en la medida en que se manifiesta a la vivencia. La reducción consiste en el desocultamiento del modo de ser la vivencia para el ente y el ente para la vivencia.

Lejos de encerrarnos "dentro" de la conciencia, el método fenomenológico ha abierto la conciencia y el ente al ámbito pleno de claridad de la evidencia; en él todo es patente, nada oculto; en él nada se reserva en sí mismo, todo se entrega. "Por lo tanto la reducción fenomenológica no significa algo así como la limitación de la investigación a la esfera de la inmanencia en el sentido de lo ingrediente, a la esfera de lo encerrado como ingrediente en el 'esto' absoluto de la cogitatio, significa en general la limitación a la esfera de lo que se da puramente a sí mismo; no la esfera de aquello sobre lo cual sólo se habla o que sólo se mienta, tampoco a la esfera de lo percibido, sino a la esfera de lo que, justamente en el mismo sentido en que es mentado, es también dado y dado a sí mismo en el sentido más estricto, de modo que nada de lo mentado deje de estar dado. Con una palabra, limitación a la esfera de la evidencia pura...." 45

La reducción es de por sí tan ajena al idealismo subjetivo como pudiera serlo al realismo ingenuo, porque ambas posiciones suponen la actitud natural. No es un realismo porque no explica el conocimiento a partir de la acción de una cosa en determinados procesos psíquicos separados de ella, parte de un contexto previo de referencia ya dado: la intencionalidad. Tampoco es idealismo subjetivo porque no reduce la conciencia a sus propios "contenidos". El concepto mismo de "contenido de conciencia" es insostenible: postula la conciencia como un continente cerrado, como una parte del mundo y niega, así, la evidencia. La conciencia va más allá de sus "contenidos", en el sentido de que aprehende un objeto trascendente a los actos de conocer. Conocimiento es captación del ente mismo tal como se manifiesta; el ente mismo es el correlato intencional y nada nos permite distinguir entre él y su "manifestación". La distinción entre "fenómeno" (manifestación) y "cosa en sí" (el ente mismo) no deriva de los datos originarios: se levanta, obviamente, sobre la tesis de realidad.

La reducción ha colocado la "aporía" del conocimiento en su verdadero terreno. No podemos concebir el conocimiento como la introducción de algo en la conciencia ni como la extroversión de la conciencia en las cosas. No hay un interior y un exterior de la conciencia, pues ésta no consiste en una cosa, sino

${ }^{45} I P .$, pp $60-61$. 
en una estructura de referencia entre cosas. Lo dado inmediatamente es esa estructura peculiar de referencia: la intencionalidad. Esta no puede explicarse porque es el dato primero de que parte todo conocimiento. El dato primero es la apertura. La conciencia está allá, olvidada de sí, lanzada sobre el ente que se le ofrece; su esencia consiste en señalar las cosas y referirlas entre sí. La conciencia es tensión hacia un mundo. El ente se abre, sin reservas, al acto de conciencia; su esencia consiste en mostrarse. El mundo es término de una referencia. La esencia del conocimiento consiste en el estar abierto de la vida intencional, el cual hace posible que el mundo se le abra.

Tal es el dato originario. Lo que hay que explicar es cómo llegamos a concebir ente y conciencia cual cosas separadas que sea menester conectar; lo que es lo mismo: cómo, a partir de la evidencia, llegamos a la actitud natural. La posición de realidad vela la inicial apertura; cierra sobre sí al ente y a la conciencia y luego no puede explicar cómo se abren uno al otro. La "aporía" que deriva de ella se muestra, pues, como un paladino círculo. La conciencia no tiene que salir de sí, pues su esencia consiste justamente en aprehender la trascendencia. El objeto no tiene que entrar en el sujeto, pues, en cuanto objeto intendido está dado a él. No hay dentro ni fuera; sólo hay el espacio abierto de la vida intencional, en que vivencia y objeto se encuentran referidos. 